\title{
National And Global Trend On Stem Education And Economic Development
}

\author{
Professor Francis A. Adesoji \\ Department of Science and Technology Education, \\ University of Ibadan, Ibadan
}

\begin{abstract}
The paper dealt fervently with the historical development of mathematical science since the 17th century and how STEM was anchored by this mathematical science. The nature of STEM education in the past, the present and what we should aim at in order to enhance economic development were analysed. The paper itemised what we should teach having gotten a meaningful curriculum package and how we could integrate our teaching with the society by bringing the industries and local artisans in what could be relevant to STEM. This is to say that human capital development should be our primary objective.
\end{abstract}

\section{INTRODUCTION}

There is no precise definition of 'the mathematical sciences'. The following definition was used in the 1990 report commonly known as David II report after the chairman of the committee, Edward E. David. The discipline known as mathematical sciences encompass core (or pure) and applied mathematics, plus statistics and operation research and extends to highly mathematical areas and other mathematical computer science. The theoretical branches of many other fields - for instance biology, ecology, engineering and economics - merge seamlessly with the mathematical science.

According to the 1980 Odem report, mathematical sciences overlap with many other disciplines of science, engineering and medicine and increasingly with the areas of business such as finance and marketing.

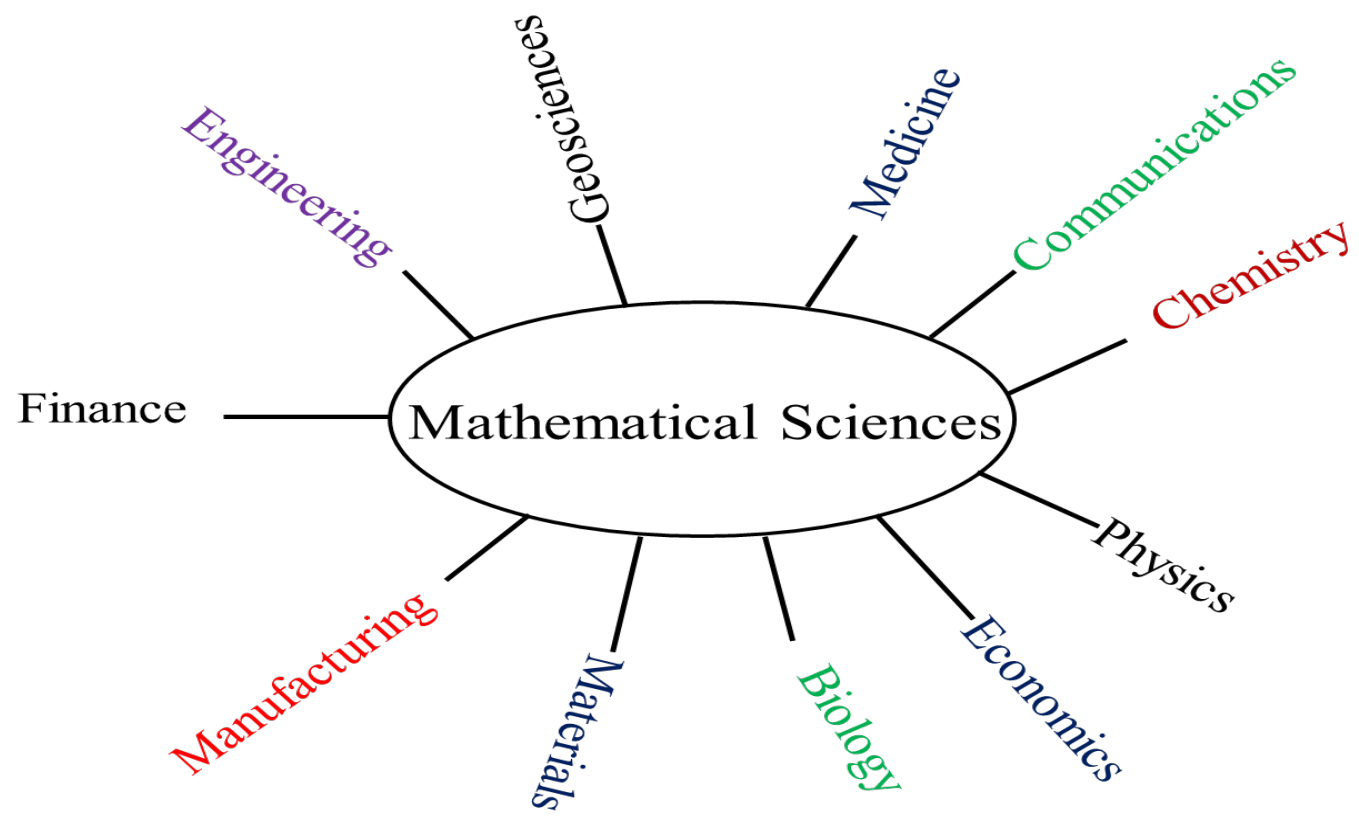


Mathematical Sciences and their interfaces. Adapted from National Science Foundation, 1998 report of the Semor Assessment panel of the US Mathematical Science, NSF, Arlington.

It could be observed that STEM are parts of mathematical science. And it could be difficult to draw line of demarcation among the four disciplines. In order to understand the nature of the disciplines, it is better to know what our situation was in the past, what our situation is now and what destination we should aspire to aim at in order to make the citizenry better off and consequently enhance economic development of the nation.

\section{OUR PAST SITUATION IN STEM}

Before and immediately after independence in 1960, the curricula of mathematical sciences were foreign in nature and were tailored towards what our colonialists wanted us to know. The popular saying is that 'teach them what is essential for them in order for them to be useful' particularly white collar jobs. In order words, it was basically essentialist philosophy. After much time, we got to the 6-3-3-4 system of education after the abrogation of A-level system. The 6-3-3-4 system is American in nature and practice if it is done rightly and it is based on the philosophy of pragma-existentialism. The most fascinating idea of it is the making use of hands to practice what is taught. But self-centeredness is not making this to materialized. Political will and economic strangulation do not pave way to the commitment it deserves.

Like I said earlier, mathematics is the anchor for the STEM disciplines. This is to say that the evolution of science played major role in the development of those discipline. Pierre de Fermat, a notable mathematician of 17 th century made important discoveries in number theory. Of significance to science was the founding of coordinate geometry by Fermat and Descartes. Remarkable contribution was however made in the 20th century. Besides, there were scientific revolution, chemical revolution, evolution of physics in the 19th century and progress in the Biological thought.

There is no doubt the fact that there has been remarkable efforts in the training of teacher, development and innovation in science, technology and science curricula generally and improvement in the assessment procedure but there is need to have a very strong relationship among the policy, the content of the curricula, the practice and the societal needs. This would have meaningful impart on the society and the knowledge of which they can benefit for STEM.

The situation as it is now is appealing right from what we have in the curricula and the end product of the dissemination of the curricula contents in the classroom. In considering what STEM can offer, therefore, relevance to the society and a clear understanding of what STEM can practice and relationship between policy and practice (Treagust, 2004). And it should be noted that there are now greater understanding and researches in the areas of STEM and United States is among one of the countries that treat research in this area as a serious field of scholarship. The National Association for Research in Science Teaching (NARST) was established in 1928 and STAN on November 30, 1957. Other teaching associations came up in the 70s. Australian Science Education Research Association held its first annual conference in 1971, the International Organization for Science and Technology Education (IOSTE) was founded in 1979 and recently, the European Science Education Research Association (ESERA) came into existence in the mid 1990s and held its first meeting in 1993.

It is important to note that through these associations, good journals were established but it is of importance to say that many scholars in black African countries do not publish their articles in journals other than local ones. And it is sad to know that because of the crazy for international papers in many institutions of learning, many which are actually of local origin 
got a website and consequently tag themselves international journals. Actually, I have a strong opinion that we should place emphasis on the quality of papers rather than looking at the location of publication. To me personally, it is not the knowledge of what is in the article that matters but its relevance to the society.

There is the need to think about alternative form of assessment in all schooling at all levels. At the secondary school level, one of the most productive in advanced countries of the world is the coalition of professional societies, employers and universities. Professional development is a way of introducing teachers to research findings but there is lack of extensive research on the effectiveness of both voluntary and required professional development. In Nigeria, the militating factors are the policy of the government and economic strangulation as a result of very low budgetary allocation to education. What we need most in our system are the good materials for effective delivery system. These include curricula, teachers' guides, educational documents - based on the findings of educational research. This is done in some countries in the world but in developing countries, research works are gathering dust in the shelves in the libraries.

\section{THE NEED FOR RELEVANT STEM EDUCATION, MEANINGFUL CURRICULUM AND GOOD ASSESSMENT PROCEDURE}

The STEM education is not doing the society any good. This is because the mode of teaching and learning is characterised with rote memorization and regurgitation of what is learnt at examinations. Even after the university education, our youths look for white collar jobs because they cannot put what is learnt into practice. It is sad to see a mechanical engineer taking his vehicle to road side mechanics. This cannot stop unless we are serious with our STEM education. Our seriousness should start from the curriculum package and delivery approach in the classrooms.

Our curriculum should include interfaces between science and technology and science and society. Though some faculties in the universities like medicine and science are stereotypic and they still regiment their knowledge to old idea, this may not be the case in China, Japan and Korea; but the old ideas may not give room for pure literacy. And it is the lack of this literacy that culminated into unemployment in Nigeria. In places like Europe and America, not many of their graduates look for employment. They prefer to be employment generators rather than being employment seekers.

It is unfortunate that the goal of different science education for schools has not been achieved by many nations (Fensham, 2002). This is because the contents of the curricula as they are now are based on organization and policies. We should therefore derive socially derived contents for inclusion in the new, more relevant STEM curricula that are important to citizens' personal lives. Perhaps, we should get ourselves involved in what I can describe as the socio-political and economic aspect of the curriculum. As the situation is now, all teachers at all levels of education are conservative and enslaved in accepting the existing curriculum. In the light of this, however, since culture is the cement that binds the society together, and language is very important in any culture, we should water-down the language of the society in the STEM to reflect the culture of the people we teach.

Researchers have concluded that our pedagogical practices are masculine in nature in term of social and cultural stereotypes and that is one of the reasons why our girls perform poorly in physical sciences (GASAT conference). In non-Western countries, STEM teachers have high status but remuneration is very poor. Even in Eastern nations, science teaching is no longer a career of first choice. This should be addressed by the government. Otherwise, there would be 
shortage of STEM teachers particularly in our secondary schools. The use of ICT in teaching is very essential. For example, computer teaching is compulsory in Ekiti State schools. Perhaps, this is why they have been coming first in external examinations such as NECO.

\section{BOOSTING OUR ECONOMY THROUGH STEM EDUCATION}

It could be easily observed that there is a gulf between STEM education and other disciplines and the production sector of the economy. This should not be the case if we want our STEM to be useful to the nation and consequently, economic growth. The launch of satellite in the orbit is not enough for economic development; human capital development is what we need at this crucial period of economic strangulation. And the solution is in the curriculum package and the implementation within the four walls of the classroom and outside it.

In Brazil, ethanol produced from sugar is used as fuel to replace gasoline. This would reduce the amount they would spend on gasoline. This is science in action! Our teaching should not be for the purpose of passing examination but to practice whatever we teach. The nature of the curriculum should take students out of the classroom to the society. The link between the classroom and industries and the artisans in relevant fields is very important for economic growth.

I strongly advocate the teaching of science to all levels of our students. It should be made a compulsory subject. Professor Oye Ibidapo-Obe, a one-time Vice Chancellor of University of Lagos and former President, Academy of Science once said 'Science forms the bases of national development, if everyone were scientist, corruption would not have assumed this worrisome dimension in the country'. He further added that science is productive, precise, logical and open minded for national development. The global economy is science driven. Scientists build rather than destroy.

In conclusion, we should therefore sit back and reflect on what we are teaching in STEM over the years in order to judge as to whether we are doing it rightly or wrongly. This would go a long way to make us contribute our small quota academically, to the development of the country as teachers of STEM.

\section{References}

Adesoji, F. A. (2017). Science Education for Economic Development. A contributed paper in a book of readings in honour of Duro Afeyalemi, FSTAN. Chapter 32.

Fensham, P. J. (1987). Physical Science, Society and Technology: A case study in the Sociology of Education in Riquarts, K. (ed), Science Technology Education and the quality of life (Vol. 2) (Pp. 714-723). Kiel: Institute for Science Education, University of Kiel.

Fensham, P. J. (2002). Time to Change Drivers for Scientific Literacy. Canadian Journal of Science, Mathematics and Technology Education. 2(1)9-24.

Science: A Human Saga. An Exhibition book on the History of Science. Homi Bhabha, Mumbi

Treagust, D. F. (2004). International Trends in Science Education Research, 125-146 in Research Trends in Science, Technology and Mathematics Education. Review talks Delivered at epiSTEM-1. Dec. 13-17, International Centre, Goa. 